\title{
An epigenomic mechanism in retinoblastoma: the end of the story?
}

\author{
A Linn Murphree ${ }^{* *}$ and Timothy J Triche
}

\begin{abstract}
The role that retinoblastoma has played in our understanding of cancer biology could hardly have been imagined 40 years ago when this disease was a rare curiosity, of interest primarily because of its variable laterality, occasional dominant inheritance, frequent lethality and embyronal origin. The discovery of its cause (biallelic loss of RB1) did not offer insight to improved management. However, the recent discovery of aberrant expression of the gene encoding spleen tyrosine kinase (SYK) subsequent to widespread methylation abnormalities in retinoblastoma suggests a potential new therapy for the disease. There is more to the story, however.
\end{abstract}

\section{Retinoblastoma: the story so far}

The identification of the retinoblastoma gene $R B 1$ in 1986 [1] and the discovery of its pivotal role in cell cycle control thrust $R B 1$ and its associated disease, retinoblastoma, to the forefront of cell and cancer biology. Inactivation of both alleles of $R B 1$ is a hallmark of retinoblastoma, a rare but aggressive childhood cancer of the retina. Today, 26 years since the identification of RB1, the primary treatment of newly diagnosed retinoblastoma consists of systemic or regional chemotherapy, or enucleation (surgical removal of the eye). These approaches do not make the most of our vast knowledge of $R B 1$.

The lack of new therapies, despite extensive characterization of the $R B 1$ gene and its manifold functions, is likely to be due to rapid progression of malignancy changes that occur in intraocular retinoblastoma after tumor initiation. As clinicians and pathologists we directly observe a panoply of physical changes occurring inside an eye affected by retinoblastoma. Newly arising tumors,

\footnotetext{
*Correspondence: LMurphree@chla.usc.edu

'The Vision Center, Children's Hospital Los Angeles, Keck School of Medicine of the University of Southern California, Los Angeles, CA 90027, USA

Full list of author information is available at the end of the article
}

usually discovered in the retinas of infants with a family history of the disease, are always the same - small, soft, round, intraretinal, gray-white 'clones' - as if they were daughter cells arising from a single cell with identical growth characteristics. As these 'clones' grow, asymmetrical overgrowth appears, which may be due to clonal growth advantages, followed by focal 'nipples' that shed clumps and strings of cells into the vitreous or subretinal space. This intraocular dispersal of tumor cells is associated with further adjustment to hypoxia, allowing massive tumor growth independently of an obvious vascular supply. Eventually, as the eye fills with tumor mass, cells invade both adjacent tissues, the choroid and the optic nerve, signaling to the pathologist an increased risk to the child of metastatic disease. The molecular mechanism(s) behind these consistently observed phenotypic alterations are not understood. In light of recent findings, however, this may be about to change.

\section{Epigenetic deregulation in retinoblastoma}

In a recent article published in Nature, Michael Dyer and his group were intrigued that retinoblastoma '... progresses very quickly following RB1 inactivation' [2]. To investigate the mechanisms behind this rapid evolution they performed whole genome sequencing (WGS) of four retinoblastomas and their corresponding germline DNA. They found that the mutation rate in these four tumors was 15-fold less than in adult tumors that have previously been analyzed by WGS. The only gene found to be recurrently mutated (13\% of 42 retinoblastomas they subsequently studied to validate their findings in a larger cohort) was the BCL-6 co-repressor gene BCOR. As noted by the authors, this is significantly fewer than the number of mutations found in common adult malignancies, where widespread genomic instability and dozens of mutations are the rule [3].

The authors then evaluated epigenetic deregulation as a possible mechanism for the rapid progression of malignancy changes, using an integrative approach involving chromatin immunoprecipitation (ChIP), DNA methylation and gene expression data analysis. Of 104 genes that showed differences in expression between fetal retina tissue and retinoblastoma, 15 known cancer genes were 
shown to have significant differences. Among these, $S Y K$, which has no known function in eye development, was found to be expressed at high levels in retinoblastoma. Suppression of the SYK protein by small molecule inhibitors led to tumor cell death in vitro and in vivo, indicating 'oncogene addiction' to this kinase in the retinoblastoma cells. The authors concluded that SYK could be a promising new therapeutic target for the disease.

\section{The significance of BCOR mutations}

While the results reported by Zhang et al. [2] are indeed encouraging, SYK is unlikely to be the only answer. Epigenetic alterations are widespread in many if not most malignancies, pediatric and adult alike, as shown by recent data on adult acute myeloid leukemia and colorectal cancer $[4,5]$. In childhood cancer, aberrant methylation of chromosome 11p in Wilms' tumor, embryonal rhabdomyosarcoma, hepatoblastoma and BeckwithWiedemann syndrome (BWS) is well documented, often a consequence of uniparental disomy. Termed loss of heterozygosity (LOH), in BWS this results in excessive expression of the gene encoding insulin-like growth factor 2 (IGF2) as a result of loss of control of imprinting by DNA methylation [6]. This leads to overgrowth in BWS and the development of tumors such as rhabdomyosarcoma. However, it is important to note that widespread mutation, copy number changes and other regions of $\mathrm{LOH}$ are also found in these tumors, emphasizing that cancer is a multistep process with many associated genomic alterations. It is also true that genome-wide methylation is aberrant, as documented by the Zhang et al. study and as observed, for example, in a subset of highly malignant adult brain tumors, glioblastoma multiforme, where a hypermethylation phenotype has been associated with better prognosis $[2,7]$.

While DNA methylation is one important mechanism in epigenetic regulation of the genome, control of histone methylation and acetylation is also a key epigenetic tool. Methylation may regulate entry to gene promoter regions, but histone modifications control access to DNA overall; compact heterochromatin is transcriptionally silent while open euchromatin is active. In the retinoblastoma cases analyzed here, the incidence of BCOR mutation (13\%) is surprisingly high [2]. Although multiple mutations in any given adult cancer are common, consistent mutation of any specific gene other than TP53 or RAS, for example, is uncommon, rarely exceeding $13 \%$ [8]. This could suggest that BCOR has a key role in retinoblastoma, aside from its known gene expression repressor function related to BCL-6. In fact, BCOR has also been shown to increase methylation of H3K4 and H3K36 [9], which in turn activates transcription. Disabling mutations of $B C O R$, as reported in this study, would presumably broadly impact chromatin remodeling and thus epigenetic control of transcription. The full phenotypic implications of $B C O R$ mutations were not discussed by Zhang et al. but the potential effects on epigenetic control could form the basis of a novel mechanism underlying retinoblastoma. Specifically, the reported genome-wide aberrant methylation could well be the result of $B C O R$ mutation, or similar mechanisms in those cases with wild-type $B C O R$.

\section{A role for the non-coding genome?}

Beyond epigenetic control mechanisms, there is increasing interest in regulatory functions unrelated to the coding portion of the genome, or exome [10]. Zhang and colleagues [2] documented some hundreds of sequence variants in the non-coding portion of the genome, the impact of which cannot be deduced from exome sequencing or RNA-Seq of poly-A selected mRNAs. This 'dark matter' of the genome is largely intergenic, where these additional mutations were found. In principle, a mutation in a non-coding RNA such as H19, which controls expression of $I G F 2$, could result in the same effect as uniparental disomy and altered methylation. This principle can be extrapolated to the entirety of the transcribed genome, where tens of thousands of additional transcripts have been identified, but whose function is largely unknown. It is thus likely that the altered epigenome documented in the Zhang et al. study is a critical defect in the pathogenesis of retinoblastoma, but by no means the only one. Cancer is, after all, a multistep process, where many disparate genetic and epigenetic defects lead to a common phenotype. The identification of SYK as a potential therapeutic target is an important first step, but hardly the last.

\section{Abbreviations}

BWS, Beckwith-Wiedemann syndrome; IGF2, insulin-like growth factor 2; LOH, loss of heterozygosity; SYK, spleen tyrosine kinase.

Competing interests

The authors declare that they have no competing interests.

\section{Author details}

'The Vision Center, Children's Hospital Los Angeles, Keck School of Medicine of the University of Southern California, Los Angeles, CA 90027, USA. ${ }^{2}$ Center for Personalized Medicine, Children's Hospital Los Angeles, Department of Pathology, Keck School of Medicine of the University of Southern California, Los Angeles, CA 90027, USA.

Published: 24 February 2012

\section{References}

1. Friend SH, Bernards R, Rogelj S, Weinberg RA, Rapaport JM, Albert DM, Dryja TP: A human DNA segment with properties of the gene that predisposes to retinoblastoma and osteosarcoma. Nature 1986, 323:643-646.

2. Zhang J, Benavente CA, McEvoy J, Flores-Otero J, Ding L, Chen X, Ulyanov A, Wu G, Wilson M, Wang J, Brennan R, Rusch M, Manning AL, Ma J, Easton J, Shurtleff S, Mullighan C, Pounds S, Mukatira S, Gupta P, Neale G, Zhao D, Lu C, Fulton RS, Fulton LL, Hong X, Dooling DJ, Ochoa K, Naeve C, Dyson NJ, et al:: A novel retinoblastoma therapy from genomic and epigenetic analyses. Nature 2012, 481:329-334

3. Futreal PA, Coin L, Marshall M, Down T, Hubbard T, Wooster R, Rahman N, Stratton MR: A census of human cancer genes. Nat Rev Cancer 2004, 
4:177-183.

4. Toyota M, Ahuja N, Ohe-Toyota M, Herman JG, Baylin SB, Issa JP: CpG island methylator phenotype in colorectal cancer. Proc Natl Acad Sci U S A 1999, 96:8681-8686

5 Galm O, Wilop S, Lüders C, Jost E, Gehbauer G, Herman JG, Osieka R: Clinical implications of aberrant DNA methylation patterns in acute myelogenous leukemia. Ann Hematol 2005, 84(Suppl 1):39-46.

6. Reik W, Brown KW, Slatter RE, Sartori P, Elliott M, Maher ER: Allelic methylation of H19 and IGF2 in the Beckwith-Wiedemann syndrome. Hum Mol Genet 1994, 3:1297-1301.

7. Noushmehr H, Weisenberger DJ, Diefes K, Phillips HS, Pujara K, Berman BP, Pan F, Pelloski CE, Sulman EP, Bhat KP, Verhaak RG, Hoadley KA, Hayes DN, Perou CM, Schmidt HK, Ding L, Wilson RK, Van Den Berg D, Shen H, Bengtsson H, Neuvial P, Cope LM, Buckley J, Herman JG, Baylin SB, Laird PW, Aldape K; Cancer Genome Atlas Research Network: Identification of a CpG island methylator phenotype that defines a distinct subgroup of glioma. Cancer Cell 2010, 17:510-522.

8. Mardis ER, Ding L, Dooling DJ, Larson DE, McLellan MD, Chen K, Koboldt DC,
Fulton RS, Delehaunty KD, McGrath SD, Fulton LA, Locke DP, Magrini VJ, Abbott RM, Vickery TL, Reed JS, Robinson JS, Wylie T, Smith SM, Carmichael L, Eldred JM, Harris CC, Walker J, Peck JB, Du F, Dukes AF, Sanderson GE, Brummett AM, Clark E, McMichael JF, et al:: Recurring mutations found by sequencing an acute myeloid leukemia genome. New Engl JMed 2009, 361:1058-1066.

9. Fan Z, Yamaza T, Lee JS, Yu J, Wang S, Fan G, Shi S, Wang CY: BCOR regulates mesenchymal stem cell function by epigenetic mechanisms. Nat Cell Biol 2009, 11:1002-1009.

10. Kapranov P, St Laurent G, Raz T, Ozsolak F, Reynolds CP, Sorensen PH, Reaman G, Milos P, Arceci RJ, Thompson JF, Triche TJ: The majority of total nuclearencoded non-ribosomal RNA in a human cell is 'dark matter' un-annotated RNA. BMC Bio/ 2011, 9:86.

doi:10.1186/gm314

Cite this article as: Murphree AL, Triche TJ: An epigenomic mechanism in retinoblastoma: the end of the story? Genome Medicine 2012, 4:14. 